\title{
Research on the Construction of High-Level Professional Teachers Based on "Double First-Class" Construction
}

\author{
Haiyi Sun ${ }^{1, a}$, Ning $\mathrm{Li}^{2, \mathrm{~b}, *}$, Zhongtang Chen ${ }^{1, \mathrm{c}}$ and Shuxian Miao ${ }^{1, \mathrm{~d}}$ \\ ${ }^{1}$ College of Science, Shenyang JianZhu University, Shenyang 110168, China \\ ${ }^{2}$ College of Sciences, Northeastern University, Shenyang 110819, China \\ ashy_xx@163.com, 'lining80@163.com, cchen630609@163.com, 'dmiaoshuxian@sina.com \\ * The corresponding author
}

\begin{abstract}
Keywords: "Double first-class"; High-level professional faculty; Construction; Reform
\end{abstract}
\begin{abstract}
Objective: In order to meet the requirements for the construction of a "double first-class" tutor team and combine the existing problems and shortcomings of the training of the tutor team, this paper puts forward the countermeasures for the training of innovative graduate instructors. Methods: Combined with " double first-class " of the construction of the tutor team training problems and the insufficiency, this article, the improvement of the training environment to create a good culture conditions and reforming the content of the training, improve the cultivation quality of graduate tutor, innovative ways and forms of creative graduate tutor training countermeasures are put forward. Results: The author applied the innovative teaching strategies to the relevant majors of Northeastern University and the Shenyang Jianzhu University and achieved good Results. Conclusion: In this paper, from the combination of theory and empirical exploration on the study of university graduate student teachers, on the one hand, building the theory of creative graduate teachers training, on the one hand, put forward the construction of creative graduate tutor training agenda, teachers team construction of an innovative graduate students research has important theory value and practical guiding significance.
\end{abstract}

\section{Introduction}

In order to build an innovation-oriented country, it is imperative for China to cultivate a large number of innovative high-level talents, enhance its capacity for independent innovation, and train a number of top scientists with world-class advanced levels. Under this background, "double first-class" construction emerged at the historic moment. General secretary Xi made it clear in his report on the work of the 19th national congress that "priority should be given to developing the cause of education. Building education into a strong country is the basic project for the great rejuvenation of the Chinese nation. We will accelerate the development of first-class universities and disciplines, and achieve the connotative development of education. Therefore, the cultivation of innovative college teachers has become a realistic requirement and the call of The Times.

"Double first-class" construction is not only the need of the school to respond to the demands of The Times and national strategies, but also the need of the school to grasp new opportunities, fulfill the school's mission of running a school and improve its comprehensive strength. Centering on the core requirements of "Chinese characteristics, world-class", colleges and universities need to undertake five construction tasks, namely, constructing first-class faculty, cultivating top-notch innovative talents, improving the level of scientific research, inheriting and innovating excellent culture, and pushing forward the transformation of results. One of the key elements of cultivating high-level innovative talents is to have high-level graduate tutors. The improvement of graduate tutor ability is the key to achieve the goal of innovative graduate student training, the fundamental to improve the quality of innovative graduate student training, and the leading factor to optimize the education academic environment for graduate students. 


\section{Problems in the Cultivation of Teachers in Innovative Colleges and Universities}

At present, some achievements have been made in the construction of high-level professional teachers in innovative universities, but there is still a lack of construction and management mechanism that matches the current situation and is systematic and perfect, which has affected the development of education for full-time master's degree graduates.

Use more than culture. In recent years, a few schools have conducted on-the-job training for new teachers. However, there is no obvious emphasis on the development and improvement of teachers who have been in the post for many years. The training unit has not realized that the mentor training is not only the right of the mentor, but also the obligation of the mentor. Objectively, it leads to the disconnection between training and demand, insufficient motivation and low enthusiasm of tutor training [2].

The training content is old and the training form is single. At the present stage, the training content of graduate tutors is basically limited to the learning of the documents and policies of the superiors, and the training on the education concept, professional ethics and education teaching skills of the tutors is ignored, so that the overall quality of the tutors cannot be improved. Although many tutors have high scientific research ability and have made great achievements in their majors, they have poor teaching ability, lack of attractive lectures and poor teaching effect, which causes students' dissatisfaction with their tutors. This also reflects that the content of existing teacher training is not reasonably arranged and the training content is not determined from the actual needs. Therefore, the training content must be reformed as soon as possible to meet the needs of education teaching in colleges and universities.

Training lacks effective assessment mechanism and tracking management. At present, all colleges and universities have carried out the training project of graduate tutors, but most colleges and universities lack regular evaluation mechanism for the training and improvement of graduate tutors, emphasizing the training process rather than the training effect. There is a lack of scientific indicators and strong measures on how to accelerate the training of teachers. According to some surveys, the way most tutors participate in domestic training is to win the approval of their own school. Some instructors participate in training according to the needs or plans of colleges and universities. There are a few mentors who are purely personal.

In the mentor training, many colleges and universities have not established a complete, scientific, standardized and legal training system, and have not formed an efficient training platform for tutors, which is neither in line with international training nor able to occupy an advantage in the new round of talent competition. The university has not got rid of the traditional management mode, and has not realized the transformation to the modernized personnel training management mode. Teacher training has not changed from a general requirement to a combination of incentives and constraints in the classified management and system management.

The tutor is not motivated to participate in the training. The purpose of the tutor training is to promote the renewal of knowledge, comprehensive development and healthy development of the tutor. However, the previous training overemphasized that the mentor was a tool to achieve education goals, ignoring the fact that the mentor was a growing and developing individual. The tutor chose to be in a passive position in terms of training content, training form and training location. Tutor training for more than in the pressure of the external policy, the arrangement of the training objects are no fair, internal learning initiative failed to effectively motivate mentor, so teachers lack of initiative to participate in the training of "if mentor ask for training, more is due to external pressure, such as assessment, promotion utility color thick, no tutor personal practical needs. Moreover, as a mentor, no matter from the academic level or scientific research level is at the highest level of higher education, this honor naturally has great satisfaction. A mentor becomes an honorary title. As a result, some teachers are immersed in the existing achievements, hang up the title of tutor, and are busy with social activities and projects. Instead of teaching, they are not interested in self-improvement and do not pay attention to training. As a result, the quality of education for graduate students declines. 
Therefore, in view of the above reasons, this paper discusses a full-time master's degree graduate student teacher team construction and mentor to guide a new way to promote the ability, for the innovation of full-time professional master degree graduate education training mode, to promote the professional master's degree graduate training quality and size of the coordinated development, has the very vital significance.

\section{The Countermeasure of Cultivating Innovative Graduate Teachers}

This paper puts forward some countermeasures from the aspects of improving the training environment, reforming the training content and cultivating the innovative postgraduate teachers. As shown in the Figure 1.

Improve the training environment and create good training conditions. The environment is the external world around the individual and affects the individual spontaneously. People are influenced by the environment all their lives. Under the influence of the environment, they develop their bodies, acquire life knowledge and experience, and form various qualities. Social environment is the external objective condition for the formation of human quality, which has certain restrictive effect on the development of quality. The growth of innovative graduate tutors requires a certain atmosphere or environment, a good campus environment, including spiritual and cultural environment and material and cultural environment. In terms of spiritual and cultural environment, it is necessary to build a more open academic and cultural atmosphere with interdisciplinary infiltration, create an innovative and tolerant cultural environment, and create a teaching environment conducive to innovation [3].

Reform the training content and improve the training quality. Tutor is refers to the so-called innovative consciousness of innovation spirit and rigorous probity of doing scholarly research attitude, the creative education idea and innovation quality, has a broad knowledge and pioneering way of thinking, good at absorbing the latest education scientific results and its application in the teaching of the education, and good at creative use of advanced education technology and method to arouse and cultivate students' innovative ability of teachers. The cultivation of innovative postgraduate tutors is mainly carried out from the following aspects: cultivating the innovative consciousness and education concept of the mentor. To cultivate the teachers with good innovative quality and to cultivate the teachers with high innovative ability.

Innovative ways and forms of teaching guidance for graduate students. First of all, can take off-job training and on-the-job training combined. Off-job training can include overseas study and domestic degree programs. For the former, the disadvantages of inbreeding can be eliminated, and the benefits can be obvious, especially when studying abroad. For the latter, the trainee should not choose the original tutor as much as possible, so as to facilitate the integration of different academic schools and draw on the advantages of others. The biggest advantage of in-service education is that it can take into account the original work. If its dissertation can be combined with the major research projects being carried out, the learning effect will be better.

Secondly, it can be carried out by combining the teaching and research practice with the old and the new. Senior and senior scholars with high moral values have accumulated rich experience in teaching and research for a long time. They have high academic attainments, formed good personal characters and enjoyed a high reputation among their peers. Young graduate tutors should break through the door, learn the ideas, methods and experiences they have accumulated over the years with an open mind, and be more careful to understand their excellent scientific morality, academic vision and open-minded mind. Therefore, training graduate tutors in teaching practice and scientific research work, and improving the academic level and quality of young and middle-aged graduate tutors with the help of old and new, will achieve twice the result with half the effort.

Thirdly, teachers should conduct more academic exchanges at home and abroad. In the university, people from different departments and disciplines can be organized to tackle problems or give lectures together. Talents from different disciplines and fields can communicate with each other, learn from each other's strengths and make up for each other's weaknesses, borrow signatures from each other, and provide new ideas, new methods and new approaches for the development of traditional subjects. With 
the rapid development of science and technology, especially the development of new subjects, interdisciplinary subjects and peripheral subjects, the professional level of the tutor team is in urgent need of continuous improvement and knowledge update. This is also an important task to continue education. To solve this problem, it is very important to strengthen academic exchanges at home and abroad. In particular, the state should strongly encourage and encourage academic exchanges between tutors and foreign countries.

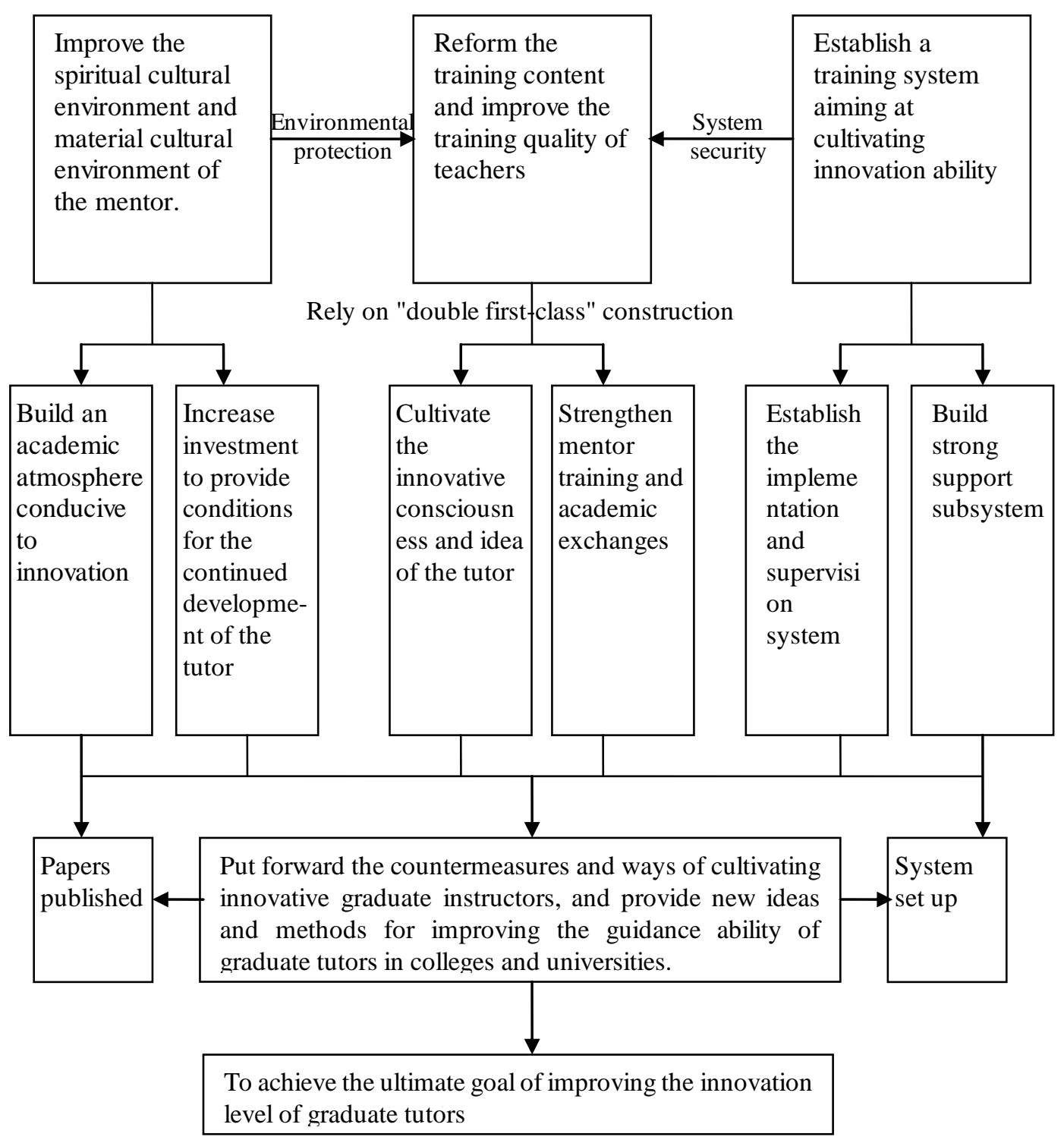

Figure 1 The construction of an innovative postgraduate guidance teacher training system

\section{Conclusions}

Higher education how to meet the needs of the development of the era of knowledge economy, and take concrete and effective measures to cultivate the graduate student's innovation ability, thus creating a large number of excellent high-level personnel to develop, dares to innovate, is undoubtedly the era have entrusted to the big responsibility of higher education, is also a graduate student teachers team construction in our country put forward the new higher request. Based on the combination of theoretical construction and empirical exploration, this paper studies the guiding teachers of postgraduates in 
colleges and universities. On the one hand, it puts forward the theory of cultivating innovative postgraduates' guiding teachers; on the other hand, it puts forward the policy plan of cultivating innovative postgraduates' guiding teachers, which can make up the deficiency of the current research on postgraduate tutors in China. Therefore, it will have important theoretical value and practical guiding significance to study the construction of innovative postgraduate guidance teachers.

\section{Acknowledgements}

This work was supported in part by the Research topic of Chinese society of academic degrees and graduate education under Grant B-2017Y0802-139, the Research project on undergraduate teaching reform of school of sciences, Northeastern University, 2018 under Grant2018003, Education innovation plan project of Shenyang Jianzhu University under Grant 2016-yb-11, the ninth batch of education first-level scientific research project of Shenyang Jianzhu University under Grant 20160124. The Fundamental Research Funds for the Central Universities under Grant N170504020.

\section{References}

[1] C.S. Jia, Z.D. Xiong, D.H. Zhou, Thoughts on strengthening the construction of postgraduate tutor team in local colleges and universities, Tianfu new theory, 6(2005) 219-221.

[2] W.J. Guo, K.S. Xiao, Building a team of mentors to train young and middle-aged mentors, Research on navigation education, 4(2016) 53-55.

[3] R. Wang, Research and thinking on the construction of doctoral supervisors, Liaoning education research,2(2006) 93-95.

[4] L. Yang, Q.G. Deng, W. Sha, et al. Exploration on the construction of postgraduate tutor team in the new era, Education exploration, 2 (2013) 76-77.

[5] G. Zheng, Exploration and practice on the construction of full-time professional degree postgraduate tutor team -- taking yangzhou university as an example, Academic Degrees \& Graduate Educatio, 11(2014) 10-14.

[6] Q. Xu, B. Ge, H.S. Deng, et al. Research and practice on the construction of postgraduate tutor team in newly-established education graduate schools, China education, 33 (2012):29-30.

[7] L.Yan, W.D. Wang, Y.J. Wang, Construction and practice of graduate tutor team based on school-enterprise co-construction engineering center, Heilongjiang education (higher education research and evaluation), 4(2014) 84-86.

[8] Q. Liu, Research on the construction of professional degree postgraduate tutor team, Education review , 2(2015) 82-84.

[9] L.J. Yu, Problems and countermeasures in the construction of postgraduate tutor team, Education and Occupation, 18 (2015) 62-64.

[10]D.X. Ma, H. Wang, J.F. Xu, Thoughts on the construction of full-time professional degree postgraduate tutor team, Higher Education Forum, 7(2015) 68-70.

[11]C.Z. Liu, Y.J. Dang, Research on the construction of postgraduate tutor team based on "standards, supervision, evaluation and service" -- taking huazhong normal university as an example, Academic Degrees \& Graduate Education, 4(2017) 22-25. 